\title{
СИСТЕМАТИЗАЦИЯ ПРАВОВОГО ОБУЧЕНИЯ ВОЕННОСЛУЖАЩИХ, ПРОХОДЯЩИХ СЛУЖБУ ПО КОНТРАКТУ, В СИСТЕМЕ ВОЕННО-ПОЛИТИЧЕСКОЙ РАБОТЫ
}

\section{SYSTEMATIZATION OF LEGAL TRAINING OF MILITARY PERSONNEL SERVING UNDER CONTRACT IN THE SYSTEM OF MILITARY-POLITICAL WORK}

K. Ivanov

Summary: The article analyzes the current practice of legal training of military employees who perform military service under contract in the Armed Forces of the Russian Federation in the system of military-political work. The main tasks of legal training in the Armed Forces of the Russian Federation are formulated. The positive and negative aspects of the work of military-political bodies to increase the level of legal awareness of military personnel are studied. References to the normative documents regulating the procedure for conducting legal training in the Armed Forces of the Russian Federation are given. The analysis of the curricula of the Ministry of Defense on legal training of military personnel is carried out. The author's proposals for improving the quality of legal training of servicemen of the Armed Forces of the Russian Federation are presented.

Keywords: legal education, legal training, legal training, military lawyers, pedagogy, legislation, Armed Forces of the Russian Federation.
Иванов Константин Валерьевич

Адъюнкт, Военный университет Министерства обороны

Российской Федерации, г. Москва

ivanov-k-v@yandex.ru

Аннотация: Проведен анализ современной практики правового обучения военнослужащих, проходящих военную службу по контракту в Вооруженных Силах Российской Федерации в системе военно-политической работы. Сформулированы основные задачи правового обучения в Вооруженных Силах Российской Федерации. Изучены положительные и отрицательные стороны работы военно-политических органов по повышению уровня правосознания военнослужащих. Приведены ссылки на нормативные документы, регламентирующие порядок проведения правового обучения в Вооруженных Силах Российской Федерации. Проведен анализ учебных планов Министерства обороны по правовому обучению военнослужащих. Представлены авторские предложения по улучшению качества правового обучения военнослужащих Вооруженных Силах Российской Федерации.

Ключевые слова: правовое просвещение, правовая подготовка, правовое обучение, военные юристы, педагогика, законодательство, Вооруженные Силы Российской Федерации.
$\Pi$ равовое обучение военнослужащих, проходящих военную службу по контракту, занимает отдельное место в системе военно-политической работы. Правовое обучение является элементом военно-социальной работы и направлено на повышение уровня правовых знаний военнослужащих, проходящих военную службу по контракту.

Правовое обучение носит в Вооруженных Силах систематический характер. Оно регламентируется приказом Министра обороны Российской Федерации от 7 декабря 2013 года № 878 «О правовом обучении в Вооруженных Силах Российской Федерации» [1], утвердившим соответствующую инструкцию. В соответствии с данной инструкцией общее руководство правовым обучением осуществляет Главное военно-политическое управление Вооруженных Сил Российской Федерации, а методическое руководство осуществляет Правовой департамент Министерства обороны Российской Федерации.

В 2018 году в Учебный план военно-политической подготовки офицеров соединений, воинских частей и организаций Вооруженных Сил Российской Федерации на 2019 год были включены всего пять тем по правовой подготовке, причем они касались финансовой грамотности, законодательства по обороту наркотических средств и материальной ответственности военнослужащих, в отдельный раздел были вынесены вопросы международного гуманитарного права. В Учебном плане военно-политической подготовки солдат (матросов), сержантов (старшин), проходящих военную службу по контракту в Вооруженных Силах Российской Федерации было определено уже одиннадцать тем по правовой подготовке, что говорит о том, что руководство военнополитических органов с большим вниманием относится к вопросу повышения правосознания военнослужащих, проходящих военную службу по контракту на должностях солдат и сержантов [2].

Необходимость правового обучения в рамках военно-социальной работы военно-политических органов вызвана необходимостью повышения уровня правосознания, адекватного восприятия военнослужащими нормативной базы, повышения правовой культуры для наиболее эффективного понимания военнослужащи- 
ми их прав и обязанностей, механизма работы законодательства Российской Федерации, касающегося всех аспектов жизни военнослужащих.

Основной задачей правового обучения является четкая, выверенная и полная подача правовых знаний военнослужащим, для осознания ими верховенства закона и необходимости следования ему.

Основные задачи правового обучения военнослужащих определены Инструкцией по организации правового обучения в Вооруженных Силах Российской Федерации, утвержденной приказом Министра обороны Российской Федерации от 7 декабря 2013 г. № 878:

- повышение уровня правовой культуры и правового воспитания военнослужащих и лиц гражданского персонала Вооруженных Сил Российской Федерации;

- изучение законодательства Российской Федерации, нормативных правовых актов Российской Федерации и Министерства обороны Российской Федерации, норм международного гуманитарного права, обязательных для Российской Федерации, необходимых для осуществления служебной деятельности, реализации прав и свобод военнослужащих, лиц гражданского персонала Вооруженных Сил Российской Федерации и исполнения ими своих обязанностей [1].

В более развернутом смысле, задачи правового обучения можно определить как:

- формирование системы правовых знаний;

- превращение полученных правовых знаний в навыки и привычки правового поведения;

- создание у военнослужащих чувства нетерпимости к нарушению закона;

- укрепления у военнослужащих чувства ответственности к исполнению своих должностных и служебных обязанностей как в мирное, так и в военное время;

- обучение личного состава защищать и отстаивать свои права, не забывая о неукоснительном соблюдении обязанностей;

- укрепление законности и правопорядка в подразделениях.

Работа военно-политических органов по правовому обучению, в значительной мере зависит от уровня педагогического мастерства и наличий необходимых знаний в праве, в способности руководителей занятий правильно донести до военнослужащих, как солдат, так и офицеров, те аспекты права и его применения, которые необходимы последним как в военной службе, так и в частной жизни.

В соответствии с планами мероприятий военно-по- литической работы проводится ряд мероприятий правового обучения:

- дважды в год проводятся месячники сплочения воинских коллективов, которые направлены на укрепление правопорядка и воинской дисциплины;

- один раз в год проводится месячник противодействия наркомании;

- три раза в год проводится неделя правовых знаний;

- ежемесячно - единый день правовых знаний;

- еженедельно (в соответствии с приказом Министра Обороны Российской Федерации от 22 июля 2019 г. № 404 [3]) - правовое информирование личного состава;

- в воинских частях и организация Воздушно-космических сил (в соответствии с приказом главнокомандующего Воздушно-космическими силами от 2 октября 2019 г. № 467) еженедельно проводится правовой час;

- ежеквартально проводятся профилактические мероприятия совместно с представителями военно-следственных органов, военной прокуратуры, федеральной службы безопасности и министерства внутренних дел.

Практика военной службы свидетельствует, что проведение любых занятий по правовому обучению эффективно, только в том случае, если командиры (начальники) не только знают правовые нормы, но и уважают их. Довольно часто, в воинских частях, удаленных от органов военного управления, командиры сами нарушают законодательство, что приводит к нежеланию военнослужащих следовать нормам закона и приводит к росту правонарушений и преступлений с их стороны. Каждый командир должен четко знать какими нормативными актами регулируются те или иные действия как его в отношении военнослужащих, так и самих военнослужащих в отношении подчиненных и начальников, кроме того, он должен осознавать правовые последствия, к которым может привести нарушение законодательства. В связи с чем особое внимание стоит уделять правовому обучению командиров (начальников), поскольку именно низкий уровень правовых знаний является причиной многих злоупотреблений и нарушений, допускаемых должностными лицами, что приводит к нарушению прав и интересов военнослужащих, и, как следствие, нежелание исполнять возложенные на них обязанности.

Действенной формой обучения военнослужащих, является изучение и анализ правоприменительной практики, решений и приговоров военных судов. Однако, существенным недостатком при такой форме правового обучения, является отсутствие комментариев специалистов, военных судей, военных прокуроров и следователей. При подготовке обзоров судебной практики, 
направляемых в воинские части и организации, представителям военных судов стоит уделять особое внимание подготовке подробных разъяснений к принятым решениям и вынесенным приговорам, для того, что бы у военнослужащих формировались более четкие представления о совершенном преступлении или правонарушении, причинах его совершения, последствиях для общества, Вооруженных Сил Российской Федерации и самого преступника (правонарушителя).

Анализ правопорядка и воинской дисциплины, разработка методических рекомендаций по их повышению, осуществляемые военно-политическими органами тесно связаны с правовым обучением личного состава, так как реализация прав и свобод, точное выполнение обязанностей военной службы возможны при наличии высокого уровня дисциплины в воинском подразделении (организации).

Военно-политические органы Вооруженных Сил Российской Федерации являются наиболее эффективными субъектами правового обучения, поскольку именно они отвечают за правопорядок и воинскую дисциплину в войсках, осуществляют взаимодействие с органами военной юстиции, федеральной службы безопасности, религиозными организациями и т.д.

Стоит отметить, что в настоящее время, значительное количество должностных лиц военно-политических органов не обладают достаточными знаниями в области права и правоприменительной практики, в связи с чем, стоит обратить внимание на повышение их уровня знаний, организацию более тесного взаимодействия с органами военной юстиции, возможность организации мероприятий по повышению их уровня знаний путем проведения занятий с военными судьями, прокурорами, следователями. Привлечение к мероприятиям правового обучения сотрудников военной правоохранительной системы частично нивелирует низкие знания специалистов военно-политических органов, однако не является оптимальным решением данной проблемы. Вариантами решения могут стать:

- увеличение количества часов правовых дисциплин в военно-учебных заведениях и их более рациональное распределение в ходе всего периода обучения курсантов;

- организация курсов повышения квалификации специалистов военно-политических органов из воинских частей (организаций) Министерства Обороны;

- участие, на систематической основе, специалистов военно-политических органов в работе военных судов, военной прокуратуры, военно-следственных органов и т.д.;

- привлечение к работе по правовому обучению специалистов военно-юридической службы (возможно, передача им некоторых функций);
- повышение уровня педагогического мастерства специалистов военно-политических органов, как самостоятельно, так и с помощью кафедр педагогики военно-учебных заведений.

Приказом Министра обороны Российской Федерации от 7 декабря 2013 г. № 878 [1] определена организация правового обучения, она включает в себя:

- анализ состояния правового обучения и правового воспитания в воинской части, выработку направлений дальнейшей работы и разработку перечня тем для обучения военнослужащих;

- разработку и утверждение планов правовой подготовки и правового воспитания военнослужащих и лиц гражданского персонала Вооруженных Сил Российской Федерации;

- изучение законодательных актов и иных нормативных правовых актов Российской Федерации и Министерства обороны Российской Федерации, международных нормативных правовых актов;

- осуществление контроля над проведением мероприятий правового обучения [1].

Основным мероприятием правового обучения военнослужащих, проходящих военную службу по контракту, является изучение правового минимума.

Правовой минимум - это минимальный набор правовых норм, которые должен знать и уметь пользоваться военнослужащий, исходя из воинского звания и занимаемой должности.

Так, правовой минимум офицеров более широк, в отличие от правового минимума прапорщиков и военнослужащих, проходящих военную службу по контракту на должностях солдат и сержантов.

В соответствии с данным приказом, сдача зачетов по правовому минимуму в виде тестов предусмотрена для всех категорий военнослужащих (кроме военнослужащих проходящих службу по призыву) один раз в два года и перед назначением на вышестоящую воинскую должность.

Учитывая постоянные изменения в законодательстве Российской Федерации (в целях его совершенствования), такая периодичность контрольных мероприятий для определения уровня знаний военнослужащих видится не совсем достаточной. Исходя из войскового опыта, военнослужащие просто заучивают основные вопросы непосредственно перед сдачей зачетов, кроме того, вариант контроля в виде тестов, не позволяет военнослужащим осмыслить требования законодательства, а приводит к бездумной зубрежке, что негативно сказывается на уровне правосознания военнослужащих. 
Довольно эффективным способом проверки уровня правовых знаний военнослужащих могли бы стать зачеты в форме решения задач, составленных для каждой категории военнослужащих, исходя из их служебного функционала по занимаемой воинской должности. При назначении же на вышестоящие воинские должности, было бы оправдано предложение по решению задач исходя из функционала предполагаемой должности.

В целях наиболее эффективной проверки уровня правовых знаний, также возможно привлечение для участия в комиссиях представителей военной прокуратуры, военных судов, военно-следственных органов, военной полиции. Специалисты, чья деятельность непосредственно связана с контролем исполнения законодательства Российской Федерации могут наиболее эффективно оценить качество правового обучения военнослужащих, проводимого командирами (начальниками) и военно-политическими органами. Кроме того, возможно привлечение указанных специалистов к подготовке материалов для проведения контроля уровня правовой подготовки военнослужащих.

В целях повышения уровня правовых знаний стоит обратить внимание на подготовку и разработку методических материалов по возникающим, в ходе осуществления служебной деятельности, вопросам. Данные материалы могут, в значительной мере, упростить работу как командиров, так и должностных лиц военно-политических органов. При этом, стоит внедрять такие методические рекомендации одновременно во всех частях и организациях Вооруженных Сил Российской Федерации, в целях унификации правоприменительной практики.

Не стоит обходить вниманием и социальные аспекты жизни в Вооруженных Силах, поскольку военно-социальная работа является одним из аспектов деятельности военно-политических органов Вооруженных Сил Российской Федерации. Довольно часто у военнослужащих возникают схожие социальные проблемы, не затрагивающие исполнение служебных обязанностей, но могущие оказать влияние на эффективность и качество военной службы: оформление наследства, разводы, разделы имущества, определение места жительства несовершеннолетнего ребенка, имущественный ущерб, причиненный третьими лицами и т.д. В целях снижения негативного воздействия данных проблем на военную службу возможна подготовка и распространение методических рекомендаций (обновляемых в ходе изменения законодательства) по порядку действия в тех или иных ситуациях. При подготовке данных рекомендаций необходимо в полной мере использовать существующую судебную и адвокатскую практику. Также обеспечить доступность таких материалов для всех военнослужащих, размещать их на стендах наглядной агитации, в «Уголках правовых знаний» и т.д.
Одним из направлений деятельности военно-политических органов по повышению уровня правовых знаний военнослужащих, является работа с обращениями и жалобами, поступающими как на имя непосредственного командира, так и в адрес вышестоящих органов военного управления. Порядок рассмотрения жалоб, заявлений и предложений военнослужащих определен главой шестой Дисциплинарного устава Вооруженных Сил [4], а также приказом Министра обороны РФ от 18 августа 2014 г. № 555 «О мерах по реализации в Вооруженных Силах Российской Федерации Федерального закона от 2 мая 2006 г. № 59-Ф3 «О порядке рассмотрения обращений граждан Российской Федерации» [5].

К большому сожалению, некоторые военнослужащие, путем направления необоснованных жалоб в адрес вышестоящих командиров (начальников), Министра обороны, Президента, создают дополнительные сложности в работе как военно-политических органов, так и органов военной юстиции, отвлекая должностных лиц от исполнения основных обязанностей. В соответствии со статьей 111 Дисциплинарного устава запрещается препятствовать подаче обращения (предложения, заявления или жалобы) военнослужащим и подвергать его за это наказанию, преследованию либо ущемлению по службе. Виновный в этом командир (начальник), так же, как и военнослужащий, подавший заведомо ложное заявление (жалобу), привлекается к ответственности в соответствии с законодательством Российской Федерации. На практике, применение законодательства Российской Федерации за подачу заведомо ложного заявления (жалобы) не происходит. Командиры (начальники) не желают возбуждать уголовные дела по статье 306 Уголовного Кодекса Российской Федерации «Заведомо ложный донос», не желая портить статистику уголовных дел в войсковой части. Такое отношение стимулирует нерадивых военнослужащих увеличивать количество обращений в адрес вышестоящих органов военного управления, снижает уровень доверия к должностным лицам воинской части. Необходимо регламентировать работу военно-политических органов в данном направлении путем передачи им дополнительных полномочий в части привлечения военнослужащих, подающих заведомо ложные и необоснованные заявления и жалобы к дисциплинарной и иной ответственности. Вводить в перечень статей Уголовного Кодекса Российской Федерации обязательных к доведению до военнослужащих и статьи, касающиеся преступлений против правосудия.

В целом, более углубленное изучение Уголовного Кодекса Российской Федерации, с наглядным ознакомлением с последствиями совершенных преступлений благотворно скажется на росте правосознания военнослужащих.

Существенным элементом правового обучения явля- 
ется, так же, наглядная агитация. Оформление «Уголка правовых знаний» должно проводиться военно-политическими органами с учетом изменений законодательства. Необходимо размещать информацию в наиболее доступной форме, избегая употребления специфических терминов без разъяснения их значения. Необходимо учитывать, что военнослужащие, в большинстве своем, не являются профессиональными юристами, в связи с чем стоит уделять внимание разъяснению законодательства, правоприменительной практики, следить за постоянной актуализацией размещенной информации. Для чего необходим постоянный контакт с органами военной юстиции, прокуратуры и военными судами. Необходимо размещение специализированной литературы и подписных изданий военно-юридической направленности. Подобная информация в значительной степени увеличивает качество самообразования военнослужащих, стимулирует их к повышению уровня правосознания.

Правовое обучение в форме проведения вечеров вопросов и ответов является факультативным, однако такой способ довольно действенный в плане повышения уровня правовых знаний у военнослужащих. При подготовке к проведению данного мероприятия у военнослужащих заранее собираются возникшие вопросы, с целью более обстоятельной подготовки ответов на них. При проведении подобных мероприятий уделяется внимание присутствию на них представителей правоохранительных органов, это позволяет избежать ошибок в ответах на поставленные вопросы, которые неизбежны, в случае отсутствия юридического образования у специалистов военно-политических органов. В обязательном порядке обобщаются и подготавливаются ответы на вопросы, возникшие в ходе проведения данного мероприятия, с доведением их до заинтересованных лиц. Зачастую, у военнослужащих возникают вопросы, которые по тем или иным причинам они стесняются озвучить в коллективе, в этом случае проводятся индивидуальные встречи и беседы с целью разрешения возникших проблем. Обязательным условием подготовки ответов на вопросы военнослужащих должна стать отсылка к нормативным актам, регламентирующим возникшие проблемы.

Для повышения эффективности правового обучения военно-политическим органам необходимо обратить внимание на повышение уровня правовой подготовки своих специалистов, поскольку только грамотный и юридически подкованных офицер может обеспечить рост уровня правосознания военнослужащих войсковой части (организации). Методами такого повышения могут стать дополнительные сборы с представителями военно-политических органов на базе военных учебных заведений, имеющих в своем составе кафедры правовых дисциплин, сотрудничество с гражданскими учебными организациями юридической направленности, допол- нительные курсы повышения квалификации, совместная работа с адвокатским образованиями в местах дислокации воинских частей и организаций.

С учетом применения воинских формирований Воздушно-космических сил в вооруженных конфликтах, а также применения их для выполнения боевых задач в международном воздушном и космическом пространстве, необходимо уделять особое внимание изучению международных правовых норм и норм международного гуманитарного права. Для этого стоит изучать опыт ведения боевых действий как Вооруженными силами Российской Федерации, так и опыт других стран. Такое обучение позволит исключить случаи возникновения международных конфликтных ситуаций. В 2018 году в Учебный план военно-политической подготовки офицеров соединений, воинских частей и организаций Вооруженных Сил Российской Федерации на 2019 год было включено всего 2 часа лекционных занятий по изучению норм международного гуманитарного права [1]. Такая форма проведения занятия и количество часов явно недостаточны для формирования устойчивых навыков у военнослужащих в правилах ведения войны.

\section{Стоит учитывать тот факт, что:}

Вооруженные Силы Российской Федерации предназначены для отражения агрессии, направленной против Российской Федерации, для вооруженной защиты целостности и неприкосновенности территории Российской Федерации, а также для выполнения задач в соответствии с федеральными конституционными законами, федеральными законами и международными договорами Российской Федерации.

В целях защиты интересов Российской Федерации и ее граждан, поддержания международного мира и безопасности формирования Вооруженных Сил Российской Федерации могут оперативно использоваться за пределами территории Российской Федерации в соответствии с общепризнанными принципами и нормами международного права, международными договорами Российской Федерации и настоящим Федеральным законом». Таким образом, изучение норм международного гуманитарного права является необходимым элементов правового обучения военнослужащих.

Военнослужащие, проходящие военную службу по контракту в частях Воздушно-космических сил, довольно часто привлекаются к выполнению миротворческих и гуманитарных миссий как в составе войск Организации Объединенных Наций, так и по решению Президента Российской Федерации. При выполнении специальных задач на территории иностранных государств, перед военно-политическими органами стоит особая задача, по формированию и поддержанию положительного имид- 
жа Вооруженных Сил Российской Федерации. С этой целью с военнослужащими, на подготовительном этапе и в ходе выполнения задач проводится работа по изучению не только норм международного гуманитарного права, но и ознакомление с законодательством страны пребывания. Данная работа требует от руководителей занятий хорошего знания преподаваемых материалов, требуется наличие методических рекомендаций по поведению военнослужащих за границей Российской Федерации. Так, для военнослужащих, выполняющих специальные задачи на территории Сирийской Арабской Республики, коллективом специалистов из Военного университета Министерства обороны Российской Федерации была подготовлена методичка по основным аспектам и особенностям, требующим особого внимания со стороны военнослужащих, пребывающих на территории этого мусульманского государства. Изучение положений, изложенных в ней, проводилось под контролем офицеров военно-политических органов.

Из вышесказанного следует, что работа по правовому обучению военнослужащих, проходящих военную службу по контракту, занимает отдельное место в деятельности военно-политических органов. Проводится систематизировано, качественно и с положительными результатами, однако органам военного управления следует обратить внимание на повышение уровня знаний офицеров военно-политических органов, ответственных за ведение подобной работы, повышение их педагогического мастерства. Стоит обратить внимание на внедрение новых, более современных и действенных методов правового обучения.

\section{ЛИТЕРАТУРА}

1. Приказ Министра обороны Российской Федерации от 7 декабря 2013 года № 878 «0 правовом обучении в Вооруженных Силах Российской Федерации» [Электронный ресурс]. Режим доступа: http://www.consultant.ru/cons/cgi/online.cgi?req=doc\&base=EXP\&n=587642\#08497387925854218

2. Армейский сборник. Журнал Министерства обороны Российской Федерации. [Электронный ресурс]. Режим доступа: https://army.ric.mil.ru/Stati/item/150488/

3. Приказ Министра обороны Российской Федерации от 22 июля 2019 г. № 404 «06 организации военно-политической работы в Вооруженных Силах Российской Федерации» [Электронный ресурс]. Режим доступа: https://vii.sfu-kras.ru/images/pdf/Prikaz_M0_RF_404.pdf

4. Дисциплинарный устав Вооруженных Сил Российской Федерации (утв. указом Президента РФ от 10 ноября 2007 г. N 1495) [Электронный ресурс]. Режим доступа: https://structure.mil.ru/files/morf/military/npa/Ustav2.pdf

5. Приказ Министра обороны РФ от 18 августа 2014 г. № 555 «0 мерах по реализации в Вооруженных Силах Российской Федерации Федерального закона от 2 мая 2006 г. № 59-Ф3 «0 порядке рассмотрения обращений граждан Российской Федерации» [Электронный ресурс]. Режим доступа: https://base.garant.ru/70747772/

6. Федеральный закон от 31.05.1996 N 61-Ф3 «06 обороне», ст. 10. [Электронный ресурс]. Режим доступа: https://base.garant.ru/135907/

(c) Иванов Константин Валерьевич (ivanov-k-v@yandex.ru). 